\title{
Psicologia e Gestão de Pessoas em Organizações de Trabalho: investigando a perspectiva estratégica de atuação
}

\author{
Psychology and People Management at Work Organizations: \\ researching the strategic action perspective
}

http://dx.doi.org/10.5007/2178-4582.2013v47n2p344

\author{
Beatriz Schmidt, Edite Krawulski e Renatto Cesar Marcondes \\ Universidade Federal de Santa Catarina, Florianópolis/SC, Brasil
}

\begin{abstract}
Este trabalho tem o objetivo de discutir as práticas do psicólogo organizacional, explorando se, e em que medida, a produção científica nacional aborda a atuação desse profissional sob uma perspectiva estratégica, aproximando, assim, a Psicologia e as práticas de gestão de pessoas em organizações de trabalho. Para tanto, realizou-se levantamento de publicações em bases de dados, a partir de descritores preestabelecidos. Os dados foram analisados quantitativa e qualitativamente, buscando articular resultados obtidos nos estudos avaliados com publicações clássicas sobre trajetória de desenvolvimento e características atuais da Psicologia Organizacional e do Trabalho. Identificou-se escassez de produções sobre atuação estratégica em gestão de pessoas, bem como interesse recente sobre a temática. Discute-se que, ao deixar de utilizar unicamente procedimentos operacionais, o profissional passa a agente de transformações organizacionais. Não obstante, o artigo aborda fatores que evidenciam que a atuação estratégica ainda representa um grande desafio ao psicólogo organizacional e do trabalho.
\end{abstract}

Palavras-chave: gestão de pessoas - psicologia organizacional e do trabalho - atuação profissional do psicólogo - gestão estratégica.
This paper aims at discussing the practices of organizational psychologist, exploring whether, and to what extent, the Brazilian scientific literature addresses the performance of this professional from a strategic perspective, thereby nearing psychology and the practices of people management in work organizations. In order to do so, we searched for publications in databases under certain keywords, or descriptors. Data were analyzed quantitatively and qualitatively, seeking to articulate the results obtained in the studies evaluated with classical publications on development trajectory and current characteristics of Organizational and Occupational Psychology. We identified shortage of papers on strategic performance in people management, as well as recent interest on the subject. We argue that the professional becomes a transformational agent when operational procedures are not the only ones to be used. Nevertheless, the article discusses factors that show that strategic action still represents a major challenge to organizational and occupational psychologists.

Keywords: people management - organizational psychology - psychologist professional practice strategic management.

\section{Introdução}

Desde as últimas décadas do século passado, significativas transformações nos contextos produtivos, decorrentes principalmente de avanços tecnológicos, bem como de modificações na estrutura e na cultura organizacional, vêm ocasionando grandes mudanças nas organizações de trabalho (DELLAGNELO; SILVA, 2000). Uma importante consequência dessas mudanças se refere ao reconhecimento da interdependência entre desempenho organizacional e pessoas que fazem parte de tal contexto. 
A literatura da área vem registrando esse reconhecimento ao enfatizar que, para prosperar, todas as organizações dependem, invariavelmente, do desempenho humano (FISCHER, 2002; ZANELLI; SILVA, 2008). As pessoas constituem fonte de vantagens competitivas, em virtude de seu valor, potencialidades e qualidades (DAVEL; VERGARA, 2008). Por conseguinte, um aspecto crucial da competitividade organizacional está relacionado aos processos de gestão de pessoas no trabalho.

Essa tendência a se reconhecer, cada vez mais, a importância do fator humano para o bom desempenho das organizações exige a adoção de um modelo de gestão de pessoas compatível com o conjunto de transformações em curso nos contextos produtivos. A expressão gestão de pessoas emergiu no final do século XX, em substituição ao termo administração de recursos humanos, considerado restritivo por referir-se às pessoas como recursos, pareados àqueles financeiros ou materiais (GIL, 2001). A gestão de pessoas, em contraste, vem sendo percebida como uma função gerencial, visando à cooperação dos trabalhadores para o alcance dos objetivos organizacionais e individuais, ou, ainda, como a maneira de organizar e gerenciar o comportamento humano no trabalho.

Contemporaneamente, o desempenho humano no trabalho tem sido valorizado com relação a características como intuição e criatividade (FISCHER, 2002); a valorização dessas características corrobora a ênfase das empresas às relações com pessoas, com seus conhecimentos, habilidades, inteligência e emoções $\square$ isto é, com a subjetividade. Para compreender a satisfação e a motivação no trabalho, sob este modelo de gestão, faz-se necessário conhecer o que é valorizado pelas pessoas integrantes das organizações (GOUVÊA; KUBO; MANTOVANI, 2011).

No entanto, fatores de diversas ordens, sobretudo econômicas, como o acirramento da concorrência entre as empresas, por exemplo, têm gerado dificuldades relativas à preservação da saúde física e psicológica do trabalhador (AZEVEDO, 1994), resultando em prejuízos à produtividade e à satisfação no trabalho. Elementos relativos a formas contemporâneas de organização e de gestão do trabalho, tais como a competitividade intra e interequipes, mecanismos sutis de controle e, ainda, a própria sobrecarga de trabalho resultante de processos de redução de quadros, igualmente constituem ameaças e/ou agravos à vida laboral saudável e satisfatória (SATO, 2002; JACQUES, 2002; HELOANI, 2010).

Nessa conjuntura de complexidade e diversidade de fatores presentes nos contextos produtivos contemporâneos, a gestão de pessoas se constitui, portanto, como componente essencial da busca pelo bem-estar, justiça organizacional e qualidade de vida dos trabalhadores. O exercício dessa atividade, ademais, requer a intervenção de profissionais preparados e que reconheçam o entrelaçamento de todas essas dimensões.

A intervenção de profissionais psicólogos em contextos organizacionais, domínio da Psicologia Organizacional e do Trabalho (POT), histo- 
ricamente tem atendido demandas clássicas referentes aos processos de gestão de pessoas, muitas vezes circunscritas ao denominado tripé recrutamento-seleção-treinamento. Recentemente, outras práticas foram incorporadas a essa atuação, como aquelas relativas à qualidade de vida, saúde e bem-estar no trabalho, expressando uma perspectiva estratégica de atuação, ou seja, alinhada às políticas e práticas organizacionais (LACOMBE; CHU, 2008). Segundo estudiosos brasileiros, a tarefa central da POT consiste em:

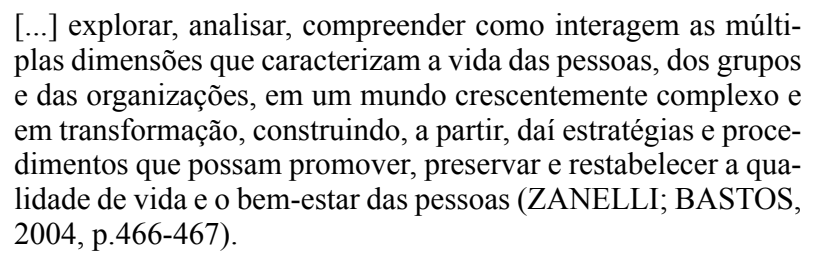

A construção de estratégias e procedimentos de intervenção visando à promoção, à preservação e ao restabelecimento da qualidade de vida e do bem-estar das pessoas em ambientes e/ou relações laborais não é tarefa de fácil cumprimento para os psicólogos da área de POT, cuja atuação sofre críticas. Tais críticas denunciam limitações da atuação nesse campo, bem como restrições que os demais campos da Psicologia lhe imputam (CODO, 1986). Remontando à década de 1980 , elas apontam a precariedade do preparo acadêmico para o exercício profissional nessa área.

Discussões a esse respeito, e, principalmente, demandas decorrentes das transformações acima referidas, apontam restrições da intervenção em POT, historicamente, ao âmbito operacional, indicando a necessidade de revisitar a prática e ampliar seu alcance, atentando aos níveis estratégico e de políticas e ao desenvolvimento de práticas que considerem não apenas o nível micro -organizacional, mas também o contextual. Na prática, intervenções nessa perspectiva se concretizam, por exemplo, em ações como o planejamento estratégico das organizações, e em posições como as diretorias de gestão de pessoas (ZANELLI; BASTOS, 2004), configurando um processo ainda em curso.

A intervenção em nível contextual se faz por ações em um modelo de renovação de práticas consolidadas, incorporação de novas práticas e ampliação do escopo de intervenção nos três grandes campos: Psicologia Organizacional, Psicologia do Trabalho e Gestão de Pessoas (BASTOS, 2005), avançando no sentido de ocupar lugares de pensar e agir estratégicos nas organizações de trabalho.

Considerando a importância da abordagem dessas questões em termos de formação, inserção e execução de atividades laborais no campo da POT, o presente artigo tem por objetivo discutir a atuação do psicólogo organizacional, buscando explorar se, e em que medida, a produção científica nacional aborda 
as práticas desse profissional sob uma perspectiva estratégica, aproximando a Psicologia e as práticas de gestão de pessoas em organizações de trabalho.

\section{Método}

A pesquisa realizada compreendeu as seguintes fases: (1) levantamento da produção científica em base de dados nacionais; (2) apreciação dos resumos dos artigos; (3) seleção dos documentos; (4) leitura das produções selecionadas; (5) definição das categorias de análise; (6) articulação dos resultados obtidos com publicações sobre a trajetória de desenvolvimento e as características atuais da POT no Brasil.

O levantamento dos artigos foi realizado em plataformas de pesquisa nacionais, especificamente nos sítios: Periódicos Eletrônicos em Psicologia (PEPsic); Index Psi (Conselho Federal de Psicologia/PUC-Campinas); e Scientific Electronic Library Online (Scielo). A busca ocorreu mediante a utilização de termos preestabelecidos (descritores), selecionados com base na terminologia em Psicologia da Biblioteca Virtual em Saúde (BVS-PSI). Após a seleção de alguns artigos e da identificação de suas palavras-chave, novos descritores foram adicionados ao levantamento. Por fim, utilizando-se o operador lógico $\square$ AND $\square$, adotou-se a combinação de dois diferentes termos dentre os seguintes: administração de recursos humanos; gestão de pessoas; Psicologia; Psicologia do trabalho; Psicologia organizacional; Psicologia organizacional e do trabalho; psicólogo; recursos humanos; estratégico; estratégica.

A identificação dos trabalhos ocorreu em novembro de 2011 e, em uma segunda etapa, com os descritores $\lceil e s t r a t e ́ g i c o \square \mathrm{e}\lceil e s t r a t e ́ g i c a \square$ em junho de 2012, a fim de atender à demanda de identificar artigos que versassem, especificamente, sobre atuações estratégicas em gestão de pessoas. Não houve delimitação quanto ao ano de publicação dessas produções.

Essas estratégias de busca conduziram a 128 resumos de produções científicas (84 disponíveis na Scielo, 36 na IndexPsi e oito no PEPsic). Excluídas as duplicatas, restaram 96 documentos, dos quais 6 foram excluídos do corpus de análise por se referirem a artigos internacionais publicados em língua estrangeira (inglês ou espanhol). Assim, foram avaliados os 90 resumos restantes, com o fito de identificar aqueles concernentes à temática da atuação do psicólogo em uma perspectiva estratégica na gestão de pessoas em organizações de trabalho. Essa avaliação permitiu identificar 15 produções concernentes ao foco do estudo.

Do ponto de vista quantitativo, a análise dessas 15 produções pautou-se por quatro categorias: ano de publicação; método (revisão de literatura ou levantamento de dados); técnicas (revisão sistemática, revisão não sistemática, estudo de caso, survey, pesquisa exploratória, entrevista, combinação de duas ou mais técnicas); e abordagem de dados (quantitativa, qualitativa ou quanti-qualitativa). 


\section{Resultados e discussão}

Dos 15 estudos selecionados, um foi publicado na década de 1980, dois em 1990, e 12 restantes foram publicados a partir de 2000. Tal resultado indica que o interesse por estudos sobre gestão de pessoas é recente, uma vez que a maioria ocorreu na última década. É possível, ainda, levantar a hipótese de que o atual movimento de disponibilização de produções científicas em formato eletrônico favorece o acesso ao conhecimento produzido. Os periódicos nos quais as 15 publicações foram disponibilizadas estão indicados na Tabela 1.

Tabela $1 \square$ Periódicos e frequência de artigos publicados

\begin{tabular}{|l|c|}
\hline Periódicos & N \\
\hline Revista de Administração Contemporânea & 3 \\
\hline Revista de Administração da Universidade Presbiteriana Mackenzie & 2 \\
\hline Revista Psicologia: Organizações e Trabalho & 2 \\
\hline Gestão e Produção & 1 \\
\hline Interface: Comunicação, Saúde e Educação & 1 \\
\hline Psico & 1 \\
\hline Psicologia Argumento & 1 \\
\hline Psicologia: Teoria e Pesquisa & 1 \\
\hline Revista de Administração de Empresas & 1 \\
\hline Revista de Administração Pública & 1 \\
\hline Revista Produção & 1 \\
\hline
\end{tabular}

Contempla-se, na Tabela 2, o título dos artigos selecionados, seus autores e ano de publicação.

Tabela $2 \square$ Título dos artigos, autores e ano de publicação

\begin{tabular}{|l|l|}
\hline Título & $\begin{array}{l}\text { Autores (ano de } \\
\text { publicação) }\end{array}$ \\
\hline $\begin{array}{l}\text { Desenvolvimento e validação da Escala de Percepção } \\
\text { de Políticas de Gestão de Pessoas }\end{array}$ & Fiuza (2011) \\
\hline $\begin{array}{l}\text { O estado da arte da pesquisa brasileira em Psicologia } \\
\text { do Trabalho e Organizacional }\end{array}$ & $\begin{array}{l}\text { Borges-Andrade e } \\
\text { Pagotto (2010) }\end{array}$ \\
\hline $\begin{array}{l}\text { Políticas de gestão de pessoas, valores pessoais e justi- } \\
\text { ça organizacional }\end{array}$ & Fiuza (2010) \\
\hline
\end{tabular}




\begin{tabular}{|c|c|}
\hline $\begin{array}{l}\text { A gestão de recursos humanos em uma instituição pú- } \\
\text { blica brasileira de ciência e tecnologia em saúde: o caso } \\
\text { da Fiocruz }\end{array}$ & $\begin{array}{l}\text { Mello e Amâncio } \\
\text { Filho (2010) }\end{array}$ \\
\hline $\begin{array}{l}\text { As quatro faces do RH: analisando a performance da } \\
\text { gestão de recursos humanos no Brasil }\end{array}$ & \begin{tabular}{|l|} 
Tanure, Evans e \\
Cançado (2010)
\end{tabular} \\
\hline $\begin{array}{l}\text { Análise de situação dos recursos humanos da vigilância } \\
\text { sanitária em Salvador - BA, Brasil }\end{array}$ & $\begin{array}{l}\text { Leal e Teixeira } \\
(2009)\end{array}$ \\
\hline $\begin{array}{l}\text { Políticas e práticas de gestão de pessoas: as abordagens } \\
\text { estratégica e institucional }\end{array}$ & \begin{tabular}{|l}
$\begin{array}{l}\text { Lacombe e Chu } \\
(2008)\end{array}$ \\
\end{tabular} \\
\hline $\begin{array}{l}\text { Impactos da tecnologia na gestão de pessoas: um estu- } \\
\text { do de caso }\end{array}$ & $\begin{array}{l}\text { Mascarenhas, Vas- } \\
\text { concelos e Vas- } \\
\text { concelos (2005) }\end{array}$ \\
\hline $\begin{array}{l}\text { Relacionamento interpessoal: da obra de Robert Hinde } \\
\text { à gestão de pessoas }\end{array}$ & $\begin{array}{l}\text { Ventorini e Garcia } \\
(2004)\end{array}$ \\
\hline $\begin{array}{l}\text { A carreira profissional e seus movimentos: revendo } \\
\text { conceitos e formas de gestão em tempos de mudanças }\end{array}$ & Tolfo (2002) \\
\hline A guerra do sucesso pelos talentos humanos & Leonardo (2002) \\
\hline $\begin{array}{l}\text { Empowerment: ciclo de implementação, dimensões e } \\
\text { tipologia }\end{array}$ & Rodrigues (2001) \\
\hline $\begin{array}{l}\text { Contribuições de recursos humanos para a competitivi- } \\
\text { dade em qualidade: estudo de caso }\end{array}$ & $\begin{array}{l}\text { Santos, Carpi- } \\
\text { netti e Gonçalves } \\
(1997)\end{array}$ \\
\hline $\begin{array}{l}\text { As diferentes concepções da natureza humana subja- } \\
\text { centes à administração de recursos humanos }\end{array}$ & Tolfo (1992) \\
\hline $\begin{array}{l}\text { Recursos humanos num contexto multidisciplinar: de- } \\
\text { safios de dilemas do psicólogo organizacional }\end{array}$ & Galli (1980) \\
\hline
\end{tabular}

A análise das temáticas dos estudos, considerando suas fontes, mostrou a ampliação de ocorrências em revistas do campo da Administração quando se procedeu à inclusão dos descritores एestratégico $\square \mathrm{e}$ estratégica $\square$ Esse dado indica que as produções científicas sobre gestão estratégica de pessoas são publicadas majoritariamente em periódicos desse campo. Sugere também que o interesse dos psicólogos sobre o tema é recente, especialmente ao se sopesar o baixo número de estudos encontrados em periódicos da área.

As abordagens metodológicas adotadas ficaram distribuídas entre Levantamento de Dados e Revisão de Literatura, conforme evidencia a Tabela 3. Predominou a Revisão não sistemática da literatura, com cinco ocorrências, seguida por Estudo de caso, com três ocorrências. A análise dos dados caracterizou-se, prioritariamente, como qualitativa, constando na maioria das produções (dez delas). Frisa-se a identificação de apenas um estudo cuja técnica consistiu em Revisão sistemática da literatura; igualmente, somente uma publicação contemplou a análise quantitativa e qualitativa dos dados, 
o que sugere a relevância de pesquisas com essas características, como a proposta no presente artigo.

Tabela $3 \square$ Métodos, técnicas utilizadas e análise de dados

\begin{tabular}{|c|c|}
\hline Variável & $\mathbf{N}$ \\
\hline \multicolumn{2}{|l|}{ Método } \\
\hline Levantamento de dados & 8 \\
\hline Revisão da literatura & 7 \\
\hline \multicolumn{2}{|l|}{ Técnica } \\
\hline Estudo de caso & 3 \\
\hline Revisão sistemática da literatura & 1 \\
\hline Revisão não sistemática da literatura & 5 \\
\hline Survey & 1 \\
\hline Pesquisa exploratória & 1 \\
\hline Escala & 1 \\
\hline Entrevista & 1 \\
\hline Combinação & 2 \\
\hline \multicolumn{2}{|c|}{ Análise de Dados } \\
\hline Qualitativa & 10 \\
\hline Quantitativa & 4 \\
\hline Qualitativa e quantitativa & 1 \\
\hline
\end{tabular}

Salienta-se, também, que a adoção dos termos ¿estratégico $\square$ e Testratégica $\square$ elevou a incidência do método de Levantamento de dados e da técnica de Estudo de caso. Tais resultados potencialmente remetem ao interesse dos pesquisadores de buscar, em campo, a gestão de pessoas sob uma perspectiva estratégica. Especificamente quanto aos estudos de caso, considera-se tal técnica uma maneira de acessar diretamente os dados com o desenvolvimento de pesquisas em organizações específicas, capturando e analisando as características que compõem a perspectiva estratégica de atuação em gestão de pessoas.

\section{Transformações no conceito e nas práticas de gestão de pessoas: cami- nhos para a atuação estratégica do psicólogo no campo da POT}

Os resultados qualitativos obtidos, bem como sua articulação com publicações sobre a trajetória de desenvolvimento e as características atuais da POT no Brasil, revelaram uma tendência de produções que se referem a mudanças ocorridas no conceito e nas práticas de gestão de pessoas, bem como no modo 
como elas se apresentam entre as dimensões operacional e estratégica dessas práticas. A análise desses resultados possibilitou identificar dificuldades na gestão de pessoas (obstáculos para mudanças) e inovações conceituais e práticas nesse contexto.

A primeira estratégia de busca identificou artigos que discutem as diferentes concepções da natureza humana na gestão de pessoas, além dos desafios encontrados por psicólogos e administradores em gerir equipes multidisciplinares. Tolfo (1992) retoma a discussão acerca das diferentes concepções sobre a natureza humana no trabalho, a Teoria Administrativa e os equívocos cometidos pelos profissionais, sinalizando para intervenções alternativas que promovam a natureza humana. Já o estudo de Galli (1980) trata da complexidade que equipes multidisciplinares acrescem à gestão, apontando os principais obstáculos enfrentados, além de discutir uma solução participativa, formativa e interativa, partindo do profissional psicólogo.

Especificamente no que concerne às dificuldades na gestão de pessoas, constatou-se a existência de uma produção sobre análise de setor de recursos humanos de organização pública, e um estudo crítico sobre abordagem estratégica na gestão de pessoas. Leal e Teixeira (2009) identificaram obstáculos que fazem com que o setor de recursos humanos de instituições públicas não ocupe papel estratégico: faltam programas estimuladores da multiprofissionalidade, de formação e aprendizagem organizacional, bem como são informais as ferramentas reguladoras de atividades e resultados, tal como plano de cargos e salários e código de ética. Em perspectiva diversa, Lacombe e Chu (2008) discutem o excesso de produções fortalecendo o conceito da abordagem estratégica, criticando-o como uma forma de manutenção dos interesses apenas corporativos. Em contraposição, sugerem uma abordagem institucional calcada na compreensão das forças internas da organização e da contextualização, qualificando-a como complementar à abordagem estratégica.

Os resultados obtidos na segunda estratégia de busca, apesar do número reduzido, indicam as dificuldades encontradas por sistemas de gestão de pessoas não desenvolvidos com base na contextualização, na multiprofissionalidade e na comunicação clara e eficiente. Comparativamente, as duas estratégias pareceram entrar em consonância teórica, haja vista a compreensão propositiva crítica e os principais obstáculos envolvidos.

Para melhor elucidar os obstáculos enfrentados na inserção e na trajetória de desenvolvimento da atuação do psicólogo em organizações de trabalho, recuperam-se as raízes históricas da POT, constituídas no processo de industrialização do final do século XIX e início do século XX, e que se relacionam também com o despontar da Psicologia como ciência e profissão (LIMA; COSTA; YAMAMOTO, 2011; ZANELLI; BASTOS, 2004). Embora esse campo tenha se estabelecido atrelado ao desenvolvimento da própria Psicologia, seu exercício antecedeu à teorização e à regulamentação da profissão (BASTOS; MARTINS, 1990), pois muito antes do seu reconhecimento, profissionais com conhecimentos em POT já realizavam atividades como seleção de pessoal, sobretudo por meio da aplicação de testes psicológicos. 
Atualmente, as atividades do psicólogo POT implicam níveis diferentes de intervenção - técnico, estratégico e político - e contemplam um conjunto de movimentos inovadores que incluem práticas consolidadas, renovadas em seus procedimentos, incorporação de novas práticas ampliando as propostas de intervenção e, ainda, modificações no nível da intervenção frente aos problemas organizacionais e do trabalho (BASTOS, 2005). Para este autor, nesse último movimento, o psicólogo passa a contribuir para as decisões estratégicas, lidando com os grupos, com as condições e relações de trabalho e com processos complexos de tomada de decisão, chegando a tratar dos aspectos globais da organização: “ [...] sua inserção deixa de ser superficial e aproxima-se do nível estratégico e da formulação de políticas organizacionais $\square$ (BASTOS, 2005, p. 190).

As tarefas concernentes à perspectiva estratégica de atuação do psicólogo se relacionam à assessoria a outras instâncias da empresa (chefias e diretorias, por exemplo) na intervenção sobre o comportamento organizacional (FISCHER, 2002). A gestão estratégica de pessoas requer um planejamento derivado e consoante com o planejamento estratégico da organização; as ações de gestão de pessoas com caráter estratégico devem se basear nas políticas da empresa, sua cultura, missão, visão e valores (ZIMATH, ZIMMERMANN; SILVEIRA, 2009), as quais devem subsidiar a elaboração das políticas de gestão. Com efeito, referências à importância de o psicólogo organizacional e do trabalho atuar em níveis decisórios e estratégicos nas organizações são pontuadas desde as décadas de 1980 e 1990 (LIMA et al., 2011). Ressaltam estes autores que a reorientação das suas atividades deveria passar, ainda, pela efetiva inserção desse profissional em equipes multidisciplinares, bem como por inovações referentes à proatividade e à postura preventiva, ao invés das tradicionais atividades reativas e remediativas.

Os artigos com foco em mudanças na gestão de pessoas abordam os temas da inserção do psicólogo no planejamento, bem como estratégias de carreira profissional, formas de gestão, novos olhares para o relacionamento interpessoal nos contextos organizacionais e, ainda, a respeito de novas tendências para a pesquisa em POT e novas políticas para a gestão da justiça organizacional. A análise do conteúdo desses estudos evidencia algumas discussões relevantes no desenvolvimento da profissão de psicólogo e, mais especificamente, no campo da POT: a intervenção do psicólogo no planejamento e estratégias de carreira profissional (TOLFO, 2002), por exemplo, aponta possibilidades de atuação desse profissional frente ao paradoxo contextual de flexibilização das relações de trabalho versus precarização do emprego formal.

Além da questão da carreira, dois fenômenos psicossociais se destacam em uma discussão consonante: relacionamento interpessoal e justiça organizacional. O primeiro, abordado por Ventorini e Garcia (2004), discute uma nova visão sobre a gestão do relacionamento interpessoal, propondo um olhar propiciador de ações mais estratégicas na administração desse fenômeno. Já Fiuza (2010) disserta sobre a relação direta entre ações referentes à justiça organizacional e à percepção de políticas de gestão de pessoas em organi- 
zações por seus colaboradores. Ainda compactuando com parte do objetivo desta subseção, Bastos (2005), ao analisar novas tendências para a pesquisa em POT, indica uma agenda estratégica para o desenvolvimento da Psicologia científica brasileira a partir de métodos, técnicas e áreas que necessitam ser mais explorados na produção de conhecimento e de tecnologia para intervenção em organizações de trabalho.

Temas como a gestão de recursos humanos em organizações de saúde, a disputa por talentos nas organizações e uma macroanálise da performance e do impacto da tecnologia nos setores de recursos humanos no Brasil, além de fenômenos como empowerment e percepção de políticas também foram encontrados. Cabe aduzir que o exame particularizado dos estudos revela um maior foco exclusivamente em atuações estratégicas dos departamentos de gestão de pessoas. Intervenções inovadoras vinculadas a empowerment, impacto da tecnologia na gestão de pessoas e a política de retenção de talentos mostraram-se como os principais diferenciais resultantes dessa estratégia de busca.

No âmbito de organizações públicas, Mello e Amâncio Filho (2010) analisaram mudanças ocorridas quando da substituição do modelo anterior de gestão baseado em competências. Na esfera privada, três estudos se destacaram: Tanure et al. (2010); Santos et al. (1997); e Mascarenhas et al. (2005). O estudo de Tanure et al. (2010) analisou os departamentos de recursos humanos a partir da visão de 172 presidentes das 500 maiores empresas do Brasil e chegou a um panorama, já descrito, de departamentos de recursos humanos puramente operacionais ou atuando em nível tático.

Santos et al. (1997) investigaram políticas estratégicas em empresas, identificando notadamente programas de educação continuada, apoio à formação de equipes, estímulo à expressão da cultura organizacional e à flexibilização das relações de trabalho e comunicação interna. O estudo de Mascarenhas et al. (2005), por sua vez, analisou o impacto da tecnologia na gestão estratégica de pessoas. Entre seus achados, incentivam a gestão de pessoas a favorecer a sociabilidade e a comunicação de procedimentos e resultados, além de caminhar para um serviço de consultoria interna, responsável pela solução de situações conflitantes.

O exame comparativo dos resultados encontrados mediante as duas estratégias de busca utilizadas permitiu constatar que, enquanto os primeiros estudos se referem a análises teóricas de carreira e fenômenos psicossociais no tocante à gestão e à pesquisa em POT no Brasil, aqueles identificados por meio da segunda estratégia apontam para o desenvolvimento de tecnologias de intervenção e gestão, indicando a utilização de informatização e multidisciplinaridade como principal ferramenta. Essa diferença parece indicar que a adoção de uma perspectiva estratégica de gestão possibilita intervenções mais concretas e que considerem a organização em seu contexto mais amplo.

As grandes correntes de gestão de pessoas no trabalho podem ser classificadas em quatro categorias principais, cada qual com suas especificidades (FISCHER, 2002). A primeira é o modelo de gestão de pessoas como depar- 
tamento pessoal, caracterizado por transações mais processuais e burocráticas. A segunda corresponde ao modelo de gestão de pessoas como gestão do comportamento humano, enfatizando a atuação sobre o comportamento das pessoas, em aspectos como integração, comprometimento, adaptabilidade e comunicação interpessoal. A terceira corrente consiste no modelo estratégico de gestão de pessoas, o qual busca a orientação estratégica para as políticas e práticas de gestão, de modo concatenado às políticas organizacionais. A quarta, por sua vez, refere-se ao modelo competitivo de gestão de pessoas, qualificado como tal em razão da necessidade de ser condizente com o ambiente de competitividade característico das organizações contemporâneas e também por privilegiar e se articular em torno de competências.

No Brasil, a maioria das organizações, principalmente aquelas de médio e grande porte, contam com um setor ou unidade de recursos humanos. Todavia, a existência desse setor não garante práticas de gestão em uma perspectiva sistêmica ou estratégica. Com frequência, tal denominação é conferida com o intento de atribuir modernidade às organizações, permanecendo, na prática, a restrição das atividades de gestão de pessoas às rotinas disciplinares e trabalhistas (GIL, 2001).

Interfaces entre áreas da Psicologia e da Administração contribuíram para que a gestão de recursos humanos passasse, a partir aproximadamente dos anos 1960, a ter um novo foco de atuação: o comportamento das pessoas. O behaviorismo e o humanismo influenciaram fortemente este processo: inicialmente, o predomínio da abordagem comportamentalista fundamentou $a$ criação dos instrumentos e métodos de avaliação e desenvolvimento de pessoas que, nas empresas, formariam o arsenal da Psicologia e da psicometria aplicadas aos procedimentos de gestão de recursos humanos $\square$ (FISCHER, 2002, p.21). Num segundo momento, a Psicologia humanista afirmou-se na teoria organizacional por meio de seu foco prioritário no comportamento humano $\square$ a escola das relações humanas predominou, nos anos 1960 e 1970, como matriz de conhecimento em gestão de pessoas.

Mudanças ocorridas nos mercados internacionais a partir de meados de 1980, somadas ao advento da era da competitividade, geraram a exigência de um novo papel da gestão de recursos humanos, resultando na estruturação de um modelo de gestão de pessoas com base em competências. Esse modelo, não obstante mantenha como núcleo de atuação o comportamento humano, diferencia-se por procurar alinhá-lo às estratégias da organização, como explica Fischer: terá de lidar com um ambiente em permanente transformação, característico dos tempos de turbulência e mudança; e, sobretudo terá de demonstrar sua capacidade de gerar, por meio das pessoas, maior competitividade para a empresa $\square(2002$, p.31).

Partindo da concepção central da importância da gestão de pessoas para a vantagem competitiva das empresas, evidenciam-se escassas, desde então, as abordagens relativas à gestão de recursos humanos que não mencionam as questões da agregação de valor e da competitividade. Levando em consideração esses aspectos, as empresas que adotam novas estratégias de gestão de 
pessoas procuram estabelecer vínculos cada vez mais consistentes com seus trabalhadores, como meio de manter assegurada sua competitividade, o que influencia o comportamento e envolvimento destes no ambiente organizacional (CARVALHO, et al., 2006).

Essa perspectiva do aumento de competitividade por meio do investimento na formação e retenção de profissionais qualificados faz emergir, assim, a estratégia nos departamentos de gestão de pessoas (ALBUQUERQUE, 2002). Além do espaço, gestores passam a destinar mais recursos financeiros ao desenvolvimento de políticas para o planejamento de pessoas, saúde e qualidade de vida do trabalhador e de gestão macro-organizacional dos fenômenos psicossociais, configurando-se, por essa via, elementos característicos do que se denomina gestão estratégica de pessoas.

Essa importância estratégica assumida pelos setores de gestão de pessoas em formular políticas decorreu, portanto, das constantes transformações nos contextos organizacionais, uma vez que a gestão estratégica de pessoas vincula-se diretamente à possibilidade de fomento de mudanças organizacionais. Um de seus pressupostos relaciona-se ao papel do fator humano, cada vez mais ressaltado no que tange à aquisição de vantagens competitivas pelas empresas (Ibid.). Se as organizações reconhecem as pessoas, de fato, como seres humanos e não apenas recursos; se as concebem como parceiras para alcançar a excelência, é natural que ocorra um aumento no comprometimento, desempenho e satisfação das pessoas, consideradas como o mais relevante fator de competitividade, qualidade e produtividade, ou seja, do sucesso ou do fracasso organizacional (ZANELLI; SILVA, 2008).

Em síntese, as transformações no conceito de gestão de pessoas trouxeram em seu bojo concepções gerenciais mais alinhadas às finalidades e resultados organizacionais, como também práticas de gestão que avançaram daquelas consideradas operacionais para ações estratégicas (MARRAS, 2000), as quais buscam integrar e compatibilizar o ideário e os objetivos de todas as áreas da empresa, de modo alinhado ao seu planejamento estratégico, introduzindo mudanças que afetam a qualidade e a produtividade do trabalho, como também a própria cultura organizacional.

Para a Psicologia, ações que buscam acessar e intervir nos diversos níveis organizacionais podem ser viabilizadas mediante a ocupação de posições mais estratégicas e menos operacionais, revertendo uma realidade na qual, nas organizações, o psicólogo muitas vezes ainda não está incluído, ou então é conhecido como um profissional cuja atuação ainda se restringe apenas ao recrutamento e à seleção. É responsabilidade dos profissionais desse campo dar visibilidade às suas possibilidades de contribuições (ZANELLI; BASTOS, 2004).

Cabe lembrar, no entanto, que essa atuação por vezes ainda incipiente decorre não apenas de restrições relativas aos nichos profissionais e às oportunidades que encontra; ela também pode ser determinada pela formação acadêmica precária nessa área (LIMA et al., 2011) que, com frequência, se revela obsoleta, por não ir além da abordagem dos processos de recrutamento, sele- 
ção e orientação profissional, deixando de discutir questões como as estratégias de gestão e o papel do psicólogo nesse escopo de atuação.

A precariedade da formação se evidencia mais fortemente, e se confirma, quando da realização dos estágios na área da POT: apesar de proporcionar aos estudantes maiores oportunidades de inserção profissional, a participação de estagiários em organizações pouco está direcionada a atuações estratégicas e promotoras de empreendedorismo, salvaguardando algumas raras organizações do terceiro setor, empresas juniores e ONGs que oferecem alguma $\square$ liberdade $\square$ de atuação (WITTER et al. 2005).

A respeito desta questão, pesquisa realizada junto a gestores de recursos humanos identificou como as principais características percebidas nos profissionais ingressantes nas empresas a falta de preparo técnico e a inexperiência. Por outro lado, a competência foi assinalada como a característica decisiva para a efetivação em um cargo. (CAMPOS et al., 2008). Embora dados empíricos sugiram que a categoria dos psicólogos é preocupada com a atualização de conhecimentos e a troca de experiências, indicando uma busca contínua pelo aperfeiçoamento profissional (YAMAMOTO et al., 2010), a deficiência e/ou os vieses da formação acadêmica impactam as experiências e as trajetórias de trabalho desses profissionais. Sendo assim, durante a formação é imprescindível que seja possibilitado ao acadêmico o contato com processos de produção de conhecimento científico, elaboração e desenvolvimento de projetos de trabalho a partir das reais (e atuais) demandas da sociedade, em uma perspectiva estratégica de atuação.

\section{Considerações finais}

As organizações de trabalho vêm reconhecendo, cada vez mais, a importância das pessoas para que seus objetivos sejam alcançados. Uma das consequências desse reconhecimento diz respeito às modificações relacionadas à forma de lidar com elas nos contextos organizacionais. A expressão administração de recursos humanos tende a ser substituída por gestão de pessoas tendo em vista que esta última ressalta a gestão como caráter de ação, e seu foco nas pessoas. Os conceitos de administração e gestão, apesar de serem utilizados como sinônimos, possuem uma diferença fundamental: na gestão, o resultado do processo a ser gerido apresenta um grau de previsibilidade menor; enquanto é possível administrar uma empresa, é possível no máximo orientar uma relação humana (FISCHER, 2002).

Partindo da maior ênfase na direção da ação humana e menor previsibilidade no resultado dos processos de gestão de pessoas, o psicólogo, com sua formação e olhar diferenciado sobre os fenômenos comportamentais, pode contribuir sobremaneira nos contextos organizacionais. Como o trabalho, invariavelmente, faz parte da vida de todos, o papel do psicólogo nas organizações de trabalho tem como objetivo a promoção, a preservação e o restabelecimento do bem-estar e da qualidade de vida de seus componentes. 
Intervir visando ao alcance desses objetivos implica a adoção de uma perspectiva estratégica de atuação. A partir deste foco, buscando a promoção da saúde no ambiente laboral, a percepção de que o psicólogo organizacional é um profissional que atua exclusivamente corroborando o processo alienação do trabalhador e de adaptação do homem à máquina precisa ser revista.

Evidentemente, não se pode esquecer que o desempenho no trabalho e a eficácia organizacional orientam a atuação do psicólogo de maneira bastante significativa desde o início da sua inserção nos contextos organizacionais. Entretanto, a partir de um modelo de intervenção estratégico, no qual se deixa de utilizar unicamente técnicas e procedimentos operacionais, ele passa a ser agente de mudanças e de transformações no universo organizacional, ao participar do planejamento de políticas e estratégias, como também ao oferecer consultoria interna às diferentes áreas (chefias e diretorias).

Caso não queira ser reconhecido exclusivamente como profissional responsável pela seleção de pessoas, precisa demonstrar de que forma pode contribuir para as transformações organizacionais. Para tanto, é imprescindível que conheça, de fato, suas possibilidades de atuação em uma perspectiva estratégica, seja em gestão de pessoas, seja em outras modalidades de práticas.

Faz-se necessário considerar, também, que o psicólogo, tanto quanto os demais trabalhadores, está implicado e precisa se adaptar ao novo contexto resultante do conjunto de transformações no mundo do trabalho ocorridas nas últimas décadas, das quais derivou a adoção de novos modelos organizacionais por parte das empresas e a consequente exposição, fragilização e precarização das relações laborais (HELOANI; MACÊDO; CASSIOLATO, 2010). Essa questão da precariedade dos vínculos de trabalho também pode influenciar a ausência ou a precariedade de uma atuação em nível estratégico por parte do psicólogo, pois atuar nesse nível requer conhecer, em profundidade, a complexa trama das organizações de trabalho com seus atores sociais envolvidos.

Atuar em uma perspectiva estratégica nos contextos organizacionais e do trabalho, diante desse estado de coisas, representa um grande desafio aos psicólogos, uma vez que sua formação acadêmica ainda é incipiente para esse tipo de atuação. Acrescente-se que tal modalidade exige a conquista de espaços efetivos de trabalho nesse campo, a habilidade para o estabelecimento de diálogos inter e transdisciplinares, a conquista do apoio e do respaldo dos gestores e da cúpula organizacional e, sobretudo, a construção de estratégias que favoreçam seu exercício profissional, bem como auxiliem, de algum modo, a empresa na consecução de suas metas. Sem dúvida é um longo caminho, mas acredita-se que ele está em curso.

\section{Referências}

ALBUQUERQUE, Lindolfo Galvão. A gestão estratégica de pessoas. In: FLEURY, Maria Tereza Leme (Org.) As pessoas na organização. São Paulo: Gente, 2002. p.35-50. 
AZEVEDO, Marco Antonio. Recrutamento e seleção $\square$ orientação para a saúde mental. Cadernos de Psicologia, Belo Horizonte, v.3, n.2, p.47-60, 1994.

BASTOS, Antônio Virgílio Bittencourt. A Psicologia no contexto das organizações: tendências inovadoras no espaço de atuação do psicólogo. In: Conselho Federal de Psicologia (Org.) Psicólogo brasileiro: construção de novos espaços. Campinas: Alínea, 2005, p.135-204.

BASTOS, Antônio Virgílio Bittencourt; MARTINS, Ana Helena Caldeira Galvão. O que pode fazer o psicólogo organizacional. Psicologia Ciência e Profissão, Brasília, v.10, n.1, p.10-18, 1990.

BORGES-ANDRADE, Jairo Eduardo; PAGOTTO, Cecília do Prado. O estado da arte da pesquisa brasileira em Psicologia do trabalho e organizacional. Psicologia: Teoria e Pesquisa, Brasília, v.26, n.especial, p.37-50, 2010.

CAMPOS, Keli Cristina de Lara et al.. Empregabilidade e competências: uma análise de universitários sob a ótica de gestores de recursos humanos. Revista Psicologia: Organizações e Trabalho, Brasília, v.8, n.2, p.159-183, 2008.

CARVALHO, Alex. et al.. A gestão de pessoas como estratégia para o comprometimento organizacional. Estudo de caso: empresa brasileira de correios e telégrafos $\square$ ECT. Revista Pesquisa e Desenvolvimento Engenharia de Produção, Itajubá, n.5, p.40-51, 2006.

CODO, Wanderley. O papel do psicólogo na organização industrial (notas sobre o $\square$ lobo mau em Psicologia). In: LANE, Sílvia; CODO, Wanderley (Orgs.) Psicologia social: o homem em movimento. São Paulo: Brasiliense, 1986, p.195-202.

DAVEL, Eduardo; VERGARA, Sílvia Constant. Gestão com pessoas, subjetividade e objetividade nas organizações. In: DAVE, Eduardo; VERGARA, Sílvia Constant (Orgs.) Gestão com pessoas e subjetividade. São Paulo: Atlas, 2008. p.31-56.

DELLAGNELO, Eloise Helena do Livramento; SILVA, Clóvis Luiz Machado. Novas formas organizacionais e o modelo burocrático de organizações. Revista de Ciências Humanas, Florianópolis, v.4, Ed. Esp., p.71-94, 2000.

FISCHER, André Luiz. Um resgate conceitual e histórico dos modelos de gestão de pessoas. In: FLEURY, Maria Tereza Leme (Org.) As pessoas na organização. São Paulo: Gente, 2002. p.11-34.

FIUZA, Gisela Demo. Políticas de gestão de pessoas, valores pessoais e justiça organizacional. Revista de Administração da Universidade Presbiteriana Mackenzie, São Paulo, v.11, n.5, p.5581, 2010.

FIUZA, Gisela Demo. Desenvolvimento e validação da Escala de Percepção de Políticas de Gestão de Pessoas (EPPGP). Revista de Administração da Universidade Presbiteriana Mackenzie, São Paulo, v.9, n.6, p.77-101, 2011.

GALLI, Tânia Mara. Recursos humanos num contexto multidisciplinar: desafios e dilemas do psicólogo organizacional. Psico, Porto Alegre, v.1, n.2, p.34-39, 1980.

GIL, Antônio Carlos. Gestão de pessoas: enfoque nos papéis profissionais. São Paulo: Atlas, 2001. 
GOUVÊA, Maria Aparecida; KUBO, Sérgio Hideo; MANTOVANI, Daielly Melina Nassif. Significado do trabalho nos setores público e privado. Revista de Ciências Humanas, Florianópolis, v.45, n.2, p.305-330, 2011.

HELOANI, José Roberto Montes. Gestão e organização no capitalismo globalizado: história da manipulação psicológica no mundo do trabalho. São Paulo: Atlas, 2010.

HELOANI, Roberto; MACÊDO, Katia Barbosa; CASSIOLATO, Rosângela. O exercício da profissão: características gerais da inserção profissional do psicólogo. In: BASTOS, Antônio Virgílio Bittencourt; GONDIM, Sônia Maria Guedes (Orgs.) O trabalho do psicólogo no Brasil. Porto Alegre: Artmed, 2010, p. 107-130.

JACQUES, Maria da Graça. Doença dos nervos — uma expressão da relação entre saúde/doença mental. In: JACQUES, Maria da Graça; CODO, Wanderley. (Orgs.) Saúde mental e trabalho: leituras. Petrópolis: Vozes, 2002. p. 98-111.

LACOMBE, Beatriz Maria Braga; CHU, Rebeca Alves. Políticas e práticas de gestão de pessoas: as abordagens estratégica e institucional. Revista de Administração de Empresas, São Paulo, v.48, n.1, p.25-35, 2008.

LEAL, Cristian Oliveira Benevides Sanches; TEIXEIRA, Carmem Fontes. Análise de situação dos recursos humanos da vigilância sanitária em Salvador - BA, Brasil. Interface $\square$ Comunicação, Saúde e Educação, Botucatu, v.13, n.3, p.167-179, 2009.

LEONARDO, Jefferson Marco Antônio. A guerra do sucesso pelos talentos humanos. Revista Produção, São Paulo, v.12, n.2, p.43-53, 2002.

LIMA, Felipe Coelho; COSTA, Ana Ludimila Freire; YAMAMOTO, Oswaldo Hajime. O exercício profissional do psicólogo do trabalho e das organizações: uma revisão da produção científica. Revista Psicologia: Organizações e Trabalho, Brasília, v.11, n.2, p.21-35, 2011.

MARRAS, Jean Pierre. Administração de recursos humanos: do operacional ao estratégico. São Paulo: Futura, 2000.

MASCARENHAS, André Ofenhejm; VASCONCELOS, Flávio Carvalho; VASCONCELOS, Isabela F. G. Impactos da tecnologia na gestão de pessoas: um estudo de caso. Revista de Administração Contemporânea, Rio de Janeiro, v.9, n.1, p.125-147, 2005.

MELLO, Márcio Luiz Braga Corrêa; AMÂNCIO FILHO, Antenor. A gestão de recursos humanos em uma instituição pública brasileira de ciência e tecnologia em saúde: o caso da Fiocruz. Revista de Administração Pública, Rio de Janeiro, v.44, n.3, p.613-636, 2010.

RODRIGUES, Cláudia Heloísa Ribeiro. Empowerment: ciclo de implementação, dimensões e tipologia. Gestão e Produção, São Carlos/SP, v.8, n.3, p.237-249, 2001.

SANTOS, Fernando César Almada; CARPINETTI, Luís Cesar Ribeiro; GONÇALVES, Marilson Alves. Contribuições de recursos humanos para a competitividade em qualidade: estudo de caso. Revista de Administração Contemporânea, Curitiba, v.1, n.3, p.121-140, 1997.

SATO, Leny. Saúde e controle no trabalho: feições de um antigo problema. In: JACQUES, Maria da Graça; CODO, Wanderley. (Orgs.) Saúde mental e trabalho: leituras. Petrópolis: Vozes, 2002, p.31-49. 
TANURE, Betânia; EVANS, Paul; CANÇADO, Vera L. As quatro faces do RH: analisando a performance da gestão de recursos humanos no Brasil. Revista de Administração Contemporânea, Curitiba, v.14, n.4, p.594-614, 2010.

TOLFO, Suzana da Rosa. As diferentes concepções da natureza humana subjacentes à administração de recursos humanos. Psicologia Argumento, Curitiba, v.10, n.11, p.73-86, 1992.

TOLFO, Suzana da Rosa. A carreira profissional e seus movimentos: revendo conceitos e formas de gestão em tempos de mudanças. Revista Psicologia: Organizações e Trabalho, Brasília, v.2, n.2, p.38-64, 2002.

VENTORINI, Beatriz; GARCIA, Agnaldo. Relacionamento interpessoal: da obra de Robert Hinde à gestão de pessoas. Revista Psicologia: Organizações e Trabalho, Brasília, v.4, n.2, p.117-144, 2004.

WITTER, Geraldina Porto et al.. Formação e estágio acadêmico em Psicologia no Brasil. In: Conselho Federal de Psicologia. Psicólogo brasileiro: construção de novos espaços. Campinas: Alínea, 2005. p.41-69.

YAMAMOTO, Oswaldo Hajime et al.. A formação básica, pós-graduada e complementar do psicólogo no Brasil. In: BASTOS, Antônio Virgílio Bittencourt; GONDIM, Sônia Maria Guedes (Orgs.) O trabalho do psicólogo no Brasil. Porto Alegre: Artmed, 2010. p.45-65.

ZANELLI, José Carlos; BASTOS, Antônio Virgílio Bittencourt. Inserção profissional do psicólogo em organizações e no trabalho. In: ZANELLI, José Carlos; BORGES-ANDRADE, Jairo Eduardo; BASTOS, Antônio Virgílio Bittencourt (Orgs.) Psicologia, organizações e trabalho no Brasil. Porto Alegre: Artmed, 2004. p.466-491.

ZANELLI, José Carlos; SILVA, Narbal. Interação humana e gestão: a construção psicossocial das organizações de trabalho. São Paulo: Casa do Psicólogo, 2008.

ZIMATH, Sofia Cieslak; ZIMMERMANN, Ellen; SILVEIRA, Valdemir. Participação do psicólogo organizacional na área de recursos humanos estratégico. Encontro Revista de Psicologia, Valinhos/SP, v.12, n.17, p.107-124, 2009.

Submissão em: 16/07/2013

Aceite em: 19/11/2013

Beatriz Schmidt é Psicóloga, Especialista em Saúde da Família e Mestre em Psicologia pela Universidade Federal de Santa Catarina. Doutoranda pelo Programa de Pós-Graduação em Psicologia da Universidade Federal do Rio Grande do Sul. Endereço para correspondência: Instituto de Psicologia $\square$ Programa de Pós-Graduação em Psicologia $\square$ Universidade Federal do Rio Grande do Sul. Endereço para correspondência: Rua Ramiro Barcelos, 2600/111. Bairro Santa Cecília. Porto Alegre/RS, Brasil. E-mail: psi.beatriz@gmail.com 
Edite Krawulski é Psicóloga, Mestre em Administração e Doutora em Engenharia de Produção $\square$ Ergonomia. Docente do Curso de Graduação e do Programa de Pós-Graduação em Psicologia da Universidade Federal de Santa Catarina.

E-mail: edite@cfh.ufsc.br

Renatto Cesar Marcondes é Psicólogo, Mestre pelo Programa de PósGraduação em Psicologia da Universidade Federal de Santa Catarina. E-mail: marcondes.renatto@gmail.com 